\title{
Clinical hyperthyroidism due to non-neoplastic inappropriate thyrotrophin secretion
}

\author{
A.W. Chan, I.A. MacFarlane, C. van Heyningen ${ }^{1}$ and P.M. Foy ${ }^{2}$
}

Departments of Endocrinology, ${ }^{1}$ Chemical Pathology and ${ }^{2}$ Mersey Regional Department of Neurological Sciences, Walton Hospital, Rice Lane, Liverpool L9 1AE. UK.

\begin{abstract}
Summary: We report a case of hyperthyroidism due to inappropriate thyrotrophin (TSH) secretion in a patient with selective pituitary resistance to thyroid hormone action. Symptoms of hyperthyroidism in patients with this disorder are usually mild, implying some peripheral tissue resistance to the metabolic effects of thyroid hormone. Our patient had unusually severe symptoms, including marked weight loss and cardiac arrythmias which required carbimazole and beta-blocker therapy for control. Somatostatin was ineffective in suppressing TSH secretion. The introduction of sensitive thyrotrophin assays should facilitate the accurate diagnosis of TSH-induced hyperthyroidism and avoid inappropriate treatment.
\end{abstract}

\section{Introduction}

The majority of patients with hyperthyroidism have a primary disorder of the thyroid gland with secondary suppression of thyrotrophin (TSH) secretion. Inappropriate secretion (IST) is an exceedingly rare cause of hyperthyroidism and may be due to either a TSH-producing thyrotroph pituitary adenoma (neoplastic IST), or relative insensitivity of the thyrotroph to negative feedback regulation by thyroid hormones (non-neoplastic IST). ${ }^{1}$ The introduction of sensitive TSH immunoassays into everyday clinical practice has facilitated the diagnosis of TSH-induced hyperthyroidism and many more cases will no doubt be uncovered.

Recognition of inappropriate TSH hypersecretion as a cause of hyperthyroidism is important because thyroid ablative procedures, such as radioiodine and partial thyroidectomy, may theoretically encourage thyrotroph hyperplasia and pituitary adenoma formation due to removal of thyroid hormone feedback suppression. Treatment of neoplastic inappropriate TSH secretion is by surgical removal of the pituitary adenoma. However, the treatment of non-neoplastic inappropriate TSH secretion is more difficult and ideally involves pharmacological suppression of pituitary TSH secretion.

We report a case of non-neoplastic inappropriate TSH secretion with severe hyperthyroidism, which illustrates many features of this condition

Correspondence: A.W. Chan, University Dept. of Medicine, Royal Liverpool Hospital, Prescot Street, Liverpool L7 8XP, UK.

Accepted: 13 March 1990 and also highlights the dilemma of deciding upon definitive treatment for this rare form of hyperthyroidism.

\section{Case report}

A 32 year old woman presented with a 1 year history of palpitations, sweating, diarrhoea, and weight loss. There was no family history of hyperthyroidism. On examination, she was clinically hyperthyroid with warm, sweaty palms and a resting pulse of 80 beats $/ \mathrm{min}$. There were no clinical signs of Graves' ophthalmopathy, acropachy or pretibial myxoedema. Total serum thyroxine (T4) was $>220 \mathrm{nmol} / \mathrm{l}$ (ref range 60-160; RIA in-house method), free thyroxine (FT4) $32.3 \mathrm{pmol} / \mathrm{l}$ (ref range 9-24.5; Amersham, UK, RIA assay), and free triiodothyronine (FT3) $13.1 \mathrm{pmol} / 1$ (ref range 2.9-8.9; Amersham UK, RIA assay), TSH varied between 4.2 and $9.3 \mathrm{mU} / 1$ (ref range $0.5-5.5$; Boots Celltech UK, RIA assay). Carbimazole $(30 \mathrm{mg} / \mathrm{day})$ with propranolol given during the first 2 weeks was commenced and symptoms and signs of hyperthyroidism resolved. When the dose of carbimazole was reduced, symptoms of hyperthyroidism, including marked weight loss of $5 \mathrm{~kg}$ over 2 months, recurred. She became clinically euthyroid again when carbimazole was increased to $20 \mathrm{mg} /$ day. Throughout these therapeutic manipulations her TSH remained in the range 5-10 mU/1 (Figure 1). The inappropriately raised TSH was confirmed by another TSH assay: $6.9 \mathrm{mU} / 1$ (ref range $<5 \mathrm{mU} / \mathrm{l}$; Southport District General Hospital UK, RIA in-house method). Further investigations showed normal thyroid binding globulins 


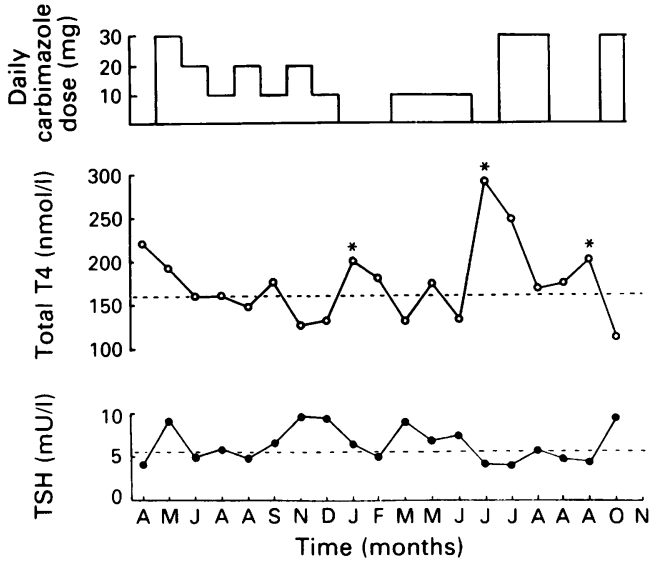

Figure 1 Details of total serum thyroxine (T4) and thyrotrophin (TSH) concentrations, and response to carbimazole over a 16 month period. There was a reciprocal relationship between T4 and TSH values, and peak levels in serum T4 whilst off carbimazole treatment (marked by ${ }^{*}$ ) coincided with troughs in serum TSH. There appeared to be an intact feedback loop which was reset to produce elevated circulating T4 in our patient.

(21 mg/l; ref range 16-28; Amersham UK, chemiluminescent assay) and thyroid receptor binding antibody $<5 \mathrm{U} / 1$ (ref range $<10$; RSR Ltd., UK). Autoantibody screening (including anti-thyroid antibodies) was negative. A ${ }^{99 m}$ Tc-pertechnetate radio-isotope thyroid scan was performed whilst the patient was off carbimazole treatment for a fortnight and this showed a diffuse goitre with an increased thyroid uptake of $18.9 \%$ at 20 minutes (normal <3\%).

The following investigations were carried out whilst off carbimazole for 2 weeks to look for a pituitary tumour, and to assess the responsiveness of the hypothalamic-pituitary-thyroid axis to a number of pharmacological agents. Computerized tomographic (CT) and magnetic resonance (MR) scans of the pituitary did not demonstrate a pituitary adenoma. The alpha subunit (alpha HCG assay)/TSH molar ratio was $<1.0$ (normal). Serum TSH rose after $200 \mu \mathrm{g}$ thyrotrophin releasing hormone (TRH) intravenously (basal 4.9, maximal $8.9 \mathrm{mU} / \mathrm{l}$ ) (Figure 2). Dexamethasone $2 \mathrm{mg}$ three times a day for 5 days failed to suppress serum TSH (basal TSH day $1=4.6 \mathrm{mU} / 1$; day $5=6.0 \mathrm{mU} / 1$. Bromocriptine $5 \mathrm{mg}$ twice a day for 7 days produced a slight fall in TSH levels (mean TSH $7.4 \mathrm{mU} / 1$ day 1 vs $5.7 \mathrm{mU} / 1$ day 7). Somatostatin (Sandostatin, SMS 201-995, Sandoz Ltd., UK) $50 \mu \mathrm{g}$ three times a day subcutaneously for 5 days failed to suppress basal TSH levels $(4.5 \mathrm{mU} / 1$ day 1 ; $5.0 \mathrm{mU} / 1$ day 5) (Figure 3) and symptoms of hyperthyroidism returned including a supraventricular tachycardia which required admission to
TRH TEST

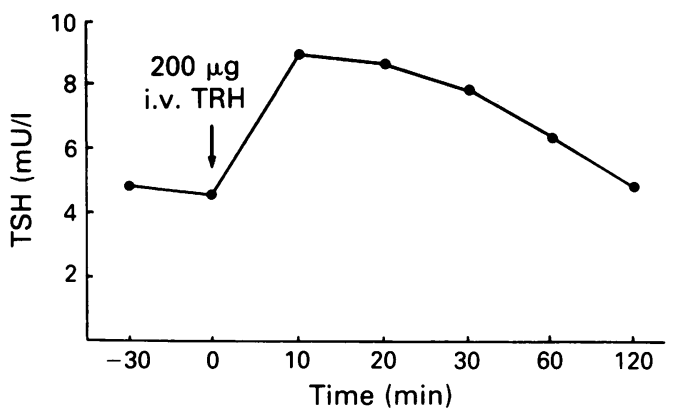

Figure 2 Thyrotrophin releasing hormone (TRH) test. After $200 \mu \mathrm{g}$ TRH intravenously there was a rapid rise in serum thyrotrophin (TSH) to over $8 \mathrm{mU} / 1$ at 10 minutes. This rapid TSH response to TRH is typical of patients with non-neoplastic TSH hypersecretion.

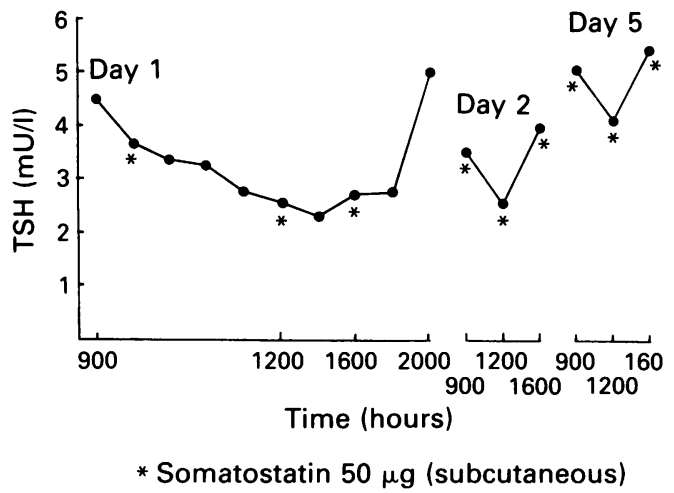

Figure 3 The effect of subcutaneous somatostatin $50 \mu \mathrm{g}$ three times/day, showing that serum TSH secretion had escaped from the inhibitory effect of somatostatin.

hospital. Somatostatin was discontinued, and carbimazole $30 \mathrm{mg}$ daily and propranolol restarted. This treatment has been continued for 12 months and she is clinically euthyroid. She refuses further trials of alternative therapy.

\section{Discussion}

Our patient had clinical hyperthyroidism and inappropriately elevated TSH levels. The differential diagnosis of inappropriate TSH secretion lies between a TSH secreting pituitary adenoma (TSHOMA or thyrotrophinoma) and non-neoplastic TSH hypersecretion. ' Inappropriate TSH secretion and hyperthyroidism in association with a pituitary adenoma was first reported in $19700^{2}$ Recent reviews have collected approximately 70 published case reports including pituitary tumours that 
secrete multiple hormones (growth hormone, prolactin, corticotrophin and gonadotrophins) as well as excess amounts of the common alpha glycoprotein hormone subunits. ${ }^{3,4}$ In the majority of cases, the pituitary tumours were large with obvious radiological abnormalities of the sella turcica at presentation. ${ }^{3}$ Only a few patients have had TSH secreting pituitary microadenomas. ${ }^{4,5}$ In our patient, radiological examinations, including CT and MR scans, have not revealed a pituitary tumour. The ratio of alpha subunit to TSH may discriminate between neoplastic and nonneoplastic inappropriate TSH secretion. ${ }^{6}$ The low alpha level with a ratio of alpha subunit/TSH of less than 1.0 in our patient is in keeping with non-neoplastic inappropriate TSH secretion.

The brisk rise in TSH following intravenous TRH and fall in TSH after 5 days bromocriptine are also compatible with non-neoplastic TSH pituitary hypersecretion. ${ }^{6,7}$ In contrast, the TSH secretion associated with pituitary adenomas is autonomous, and is not stimulated by TRH, or suppressed by bromocriptine. ${ }^{6}$ Early clinical studies have shown somatostatin to be effective in the suppression of TSH secretion in neoplastic ${ }^{8}$ and non-neoplastic inappropriate TSH secretion. ${ }^{9} \mathrm{We}$ had used a relatively modest daily dose of Sandostatin $(150 \mu \mathrm{g} /$ day for 5 days) and this may partly account for the failure to suppress TSH secretion in our patient. However, close inspection of the TSH profiles in our patient showed that there was TSH suppression on the first day of treatment, followed by escape from the inhibitory effect of Sandostatin on subsequent days (Figure 3). An earlier clinical study ${ }^{9}$ gave Sandostatin for 3 days and may not have picked up this escape phenomenon. Larger daily doses of Sandostatin ( $300 \mu \mathrm{g}$ for 5 days) used in a recent study also failed to inhibit TSH release in patients with non-neoplastic pituitary TSH hypersecretion. ${ }^{10}$

Hyperthyroidism due to non-neoplastic inappropriate TSH secretion was first reported in 1972. ${ }^{11,12}$ A recent review has collected approximately 30 published case reports ${ }^{1}$ and some were familial in origin. ${ }^{7}$ The precise underlying defect is unclear. In our patient, there was a reciprocal relationship between peaks in total serum $\mathrm{T} 4$ levels and troughs in serum TSH (Figure 1). Falling circulating thyroid hormone levels produced by anti-thyroid therapy further encouraged TSH secretion. These TSH and thyroid hormone profiles suggest that our patient had an intact feedback loop that had become reset to produce elevated circulating levels of thyroid hormones and clinical hyperthyroidism. These results support the hypothesis that non-neoplastic pituitary TSH hyperse- cretion is due to reduced sensitivity (or resistance) of pituitary thyrotrophs to the feedback inhibition by thyroid hormones. ${ }^{12}$ Therefore, supplementary amounts of exogenous T3/T4 may lower TSH secretion, ${ }^{7,13}$ but are contraindicated in a patient with symptoms of hyperthyroidism.

Patients with combined pituitary and peripheral tissue resistance to thyroid hormone action have been described, but these individuals are either euthyroid or hypothyroid. ${ }^{14}$ Symptoms of hyperthyroidism in patients with pituitary resistance but without peripheral tissue resistance to thyroid hormone action are usually mild. ${ }^{1}$ Our patient is unusual because of her severe symptoms including profound weight loss and tendency to cardiac dysrythmias whilst off anti-thyroid therapy. In the light of these severe symptoms, we thought it inappropriate to attempt suppression of pituitary TSH hypersecretion with exogenous thyroid hormones. Another therapeutic option is 3,5,3'triiodothyroacetic acid (TRIAC), a metabolite of T3 which inhibits pituitary TSH release but is virtually devoid of peripheral thyromimetic effects. ${ }^{15-17}$ However, our patient is not willing to undergo further pharmacological trials.

Although our patient remains well on carbimazole, this treatment tends to encourage further TSH secretion (Figure 1). The long term consequences of continued non-suppression of TSH secretion are not known, but may theoretically include thyrotroph hyperplasia or adenoma formation. The chronic TSH hyperstimulation in primary thyroid failure has been shown to encourage the formation of pituitary adenomas. ${ }^{18,19}$

In conclusion, this case of non-neoplastic inappropriate TSH secretion has particularly marked symptoms of hyperthyroidism indicating central (pituitary) but not peripheral tissue resistance to thyroid hormone action. We have not confirmed the earlier report on the benefit of Sandostatin in non-neoplastic inappropriate TSH secretion. ${ }^{9}$ When investigating patients with hyperthyroidism, it is important to consider the possibility of inappropriate TSH secretion.

(This case was first reported on the 8th Joint Meeting of the British Endocrine Societies, April 1989, Manchester, UK.)

\section{Acknowledgements}

We are grateful to Novo Laboratories Ltd. for their generous financial support, and to Sandoz Ltd. for supplies of Sandostatin. 


\section{References}

1. Faglia, G., Beck-Peccoz, P., Piscatelli, G. \& Medri, G. Inappropriate secretion of thyrotrophin by the pituitary. Hormone Res 1987, 26: 79-99.

2. Hamilton, C.R., Adams, L.C. \& Maloof, F. Hyperthyroidism due to thyrotrophin-producing pituitary chromophobe adenoma. N Engl J Med 1970, 283: 1077-1080.

3. Smallridge, R.C. Thyrotrophin-secreting pituitary tumours. In: Molitch, M.E. (ed.) Pituitary Tumours, Diagnosis and Management. Endocrinology and Metabolism Clinics, 1987, 16: 765-792.

4. Mashiter, K., van Noorden, S., Fahlbusch, R., Fill, H. \& Skrabal, K. Hyperthyroidism due to a TSH secreting pituitary adenoma: case report, treatment and evidence for adenoma TSH by morphological and cell culture studies. Clin Endocrinol 1983, 18: 473-483.

5. Kellett, H.A., Wyllie, A.H., Dale, B.A.B., Best, J.J.K. \& Toft, A.D. Hyperthyroidism due to a thyrotrophin-secreting microadenoma. Clin Endocrinol 1983, 19: 57-65.

6. Weintraub, B.D., Gershenghorn, M.C., Kourides, I.A. \& Fein, $H$. Inappropriate secretion of thyroid-stimulating hormone. Ann Intern Med 1981, 95: 339-351.

7. Rosler, A., Litvin, Y., Hage, C., Gross, J. \& Cerasi, E. Familial hyperthyroidism due to inappropriate thyrotrophin secretion successfully treated with triiodothyronine. J Clin Endocrinol Metab 1982, 54: 76-82.

8. Comi, R.J., Gesundheit, N., Murray, L., Gorden, P. \& Weintraub, B.D. Response of thyrotrophin-secreting pituitary adenomas to a long-acting somatostatin analogue. $N$ Engl J Med 1987, 317: 12-17.

9. Williams, G., Kraenzlin, M., Sandler, L., Burrin, J., Law, A., Bloom, S. \& Joplin, G.F. Hyperthyroidism due to nontumoral inappropriate TSH secretion. Effect of a long acting somatostatin analogue (SMS 201-995). Acta Endocrinol 1986, 113: 42-46.

10. Beck-Peccoz, P., Mariotti, S., Guillausseau, P.J. et al. Treatment of hyperthyroidism due to inappropriate secretion of thyrotrophin with the somatostatin analog SMS 201-995. J Clin Endocrinol Metab 1989, 68: 208-214.
11. Emerson, C.H. \& Utiger, R.D. Hyperthyroidism and excessive thyrotrophin secretion. $N$ Engl J Med 1972, 287: $328-333$.

12. Gershenghorn, M.C. \& Weintraub, B.D. Thyrotrophininduced hyperthyroidism caused by selective pituitary resistance to thyroid hormone: a new syndrome of 'inappropriate secretion of TSH'. J Clin Invest 1975, 56: 633-642.

13. Gharib, H., Carpenter, P.C., Scheithauer, B.W. \& Service, F.J. The spectrum of inappropriate pituitary thyrotrophin secretion associated with hyperthyroidism . Mayo Clin Proc 1982, 57: 556-563.

14. Refetoff, S. Syndromes of thyroid hormone resistance. Am J Physiol 1982, 243: E88-E98.

15. Burger, A.G., Engler, D., Sakoloff, C. \& Staeheli, V. The effects of tetraiodothyroacetic and triiodothyroacetic acids on thyroid function in euthyroid and hyperthyroid subjects. Acta Endocrinol 1979, 92: 455-467.

16. Beck-Peccoz, P., Piscatelli, G., Cattaneo, M.G. \& Faglia, G. Successful treatment of hyperthyroidism due to nonneoplastic pituitary TSH hyperthyroidism with 3,5,3'triidothyroacetic acid (TRIAC). J Endocrinol Invest 1983, 6: 217-223.

17. Salmela, P.I., Wilde, L., Juustila, H. \& Ruokonèn, A. Effects of thyroid hormones (T4, T3), bromocriptine, and TRIAC on inappropriate TSH hypersecretion. Clin Endocrinol 1988, 28: 497-507.

18. Samaan, N.A., Osbourne, B.M., Mackay, B., Leavens, M.E., Duello, T.M. \& Halmi, N.S. Endocrine and morphologic studies of pituitary adenomas secondary to primary hypothyroidism . J Clin Endocrinol Metab 1977, 45: 903-911.

19. Scheithauer, B.W., Kovacs, K., Randall, R.V. \& Ryan, N. Pituitary gland in hypothyroidism, histologic and immunocytologic study. Arch Pathol Lab Med 1985, 109: 499-504. 